High healthcare expenditures were associated with higher employment $(\mathrm{OR}=2.42$; $95 \% \mathrm{Cl}=1.53 ; 3.81)$ and lower presenteeism $(\beta=-4.53 ; \mathrm{Cl}=-8.90 ;-0.17)$. Similarly, higher GDP was associated with higher employment (OR=1.70; $95 \%$ $\mathrm{Cl}=1.02 ; 2.83)$, and in the same direction with presenteeism but without reaching statistical significance $(\beta=-3.42 ; \mathrm{Cl}=-13.07 ; 6.23)$. No significant association between any country SE indicators and absenteeism was found. At individual level, higher education was positively associated with employment-status, presenteeism and absenteeism.

Conclusions: Individual- and country-level SE factors affect work participation in $\mathrm{SpA}$, and this varies significantly across countries. Better socio-economic welfare seems to support SpA patients to stay employed and productive.

Disclosure of Interest: None declared

DOI: 10.1136/annrheumdis-2017-eular.3926

\section{OP0071 SICK LEAVE AFTER SIX MONTHS IN 664 PATIENTS WITH RECENT-ONSET INFLAMMATORY ARTHRITIS}

E.S. Norli ${ }^{1,2}$, G. Hetland Brinkmann ${ }^{2,3}$, T.K. Kvien ${ }^{2}$, S. Lillegraven ${ }^{2}$ O. Bjørneboe ${ }^{1}$, A. Julsrud Haugen ${ }^{3}$, H. Nygaard ${ }^{4}$, C. Thunem ${ }^{5}$, E. Lie $^{2}$, M.D. Mjaavatten ${ }^{2}{ }^{1}{ }^{R}$ heumatology, Martina Hansens Hospital, Sandvika; ${ }^{2}$ Rheumatology, Diakonhjemmet Hospital, Oslo; ${ }^{3}$ Rheumatology, Østfold Hospital Trust, Grålum; ${ }^{4}$ Rheumatology, Lillehammer Hospital of Rheumatic diseases, Lillehammer; ${ }^{5}$ Rheumatology, Betanien Hospital, Skien, Norway

Background: Musculoskeletal disorders, including inflammatory arthritis (IA), are among the most common reasons for work disability and sick leave. Early IA patients with risk factors for persistent and/or erosive disease, such as high swollen joint count (SJC), acute-phase reactants, RF- or ACPA-positivity, are treated aggressively to prevent joint damage and disability.

Objectives: To study the rate of sick leave according to clinical diagnosis in an unselected very early IA cohort, and to investigate whether the predictors for sick leave are the same as the known predictors for persistent and/or erosive disease. Methods: Data from the Norwegian Very Early Arthritis Clinic (NOR-VEAC), a longitudinal observational study of adults with IA of $\leq 16$ weeks' duration, were used. Exclusion criteria were arthritis due to crystal deposits, trauma, osteoarthritis and septic arthritis. For the present study we included patients eligible for work participation, i.e. $<65$ years with no retirement or disability pension, who had information about work in the baseline and six-month case report forms. Independent samples t-test, Mann-Whitney-U test or chi-square test were used as appropriate to compare patients on sick leave after 6 months with patients not reporting sick leave. Clinically relevant baseline variables with univariate $p$-value $<0.2$, as well as age and sex, were included in the multivariable logistic regression analyses with manual backwards selection to find predictors for sick leave after six months.

Results: Of 880 patients eligible for analysis $(<65$ years, no retirement or disability pension), 664 (75.5\%) had complete work participation data. Duration of joint swelling before inclusion [median (25-75 perc.)] was 35 (14-69) days, mean (SD) age 42.1 (12.1) years, $56.0 \%$ were females, $27.3 \%$ current smokers, and $22.4 \%$ anti-CCP and/or RF positive. The most common final clinical diagnoses were undifferentiated arthritis $(35.2 \%)$, rheumatoid arthritis $(22.1 \%)$ and reactive arthritis (19.7\%).

The overall rate of sick leave at presentation was $37.7 \%$ and after 6 months $23.2 \%$. More than one-third of the patients reported sick leave at first visit, regardless of diagnosis (Figure 1). At six months $>20 \%$ sick leave was still reported in all groups except sarcoid arthritis and reactive arthritis. Smoking, low education ( $\leq$ high school), longer duration of joint swelling, ACPA and RF positivity, joint pain, fatigue, patient's global assessment, SF-36 (physical and mental component summary scores), HAQ-DI and tender joint count at baseline were univariably associated with sick leave after six months, whereas SJC, ESR and CRP were not. Independent predictors were current smoking (OR $2.1(95 \%$ $\mathrm{Cl} 1.4-3.2)$ ), low education (OR $1.7(95 \% \mathrm{Cl} 1.1-2.5)$ ), longer duration of joint swelling and low SF-36 (physical and mental component summary scores).

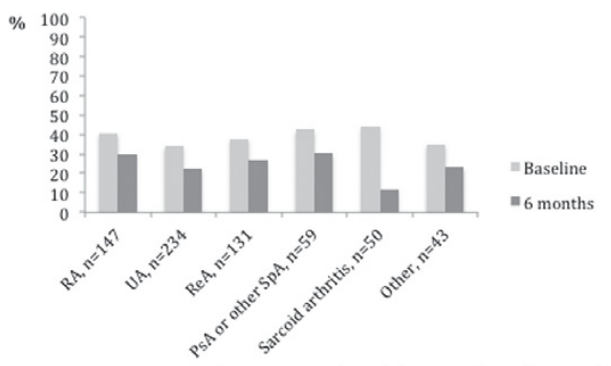

Figure 1. Proportion of patients with sick leave at baseline and after six months according to diagnosis

RA, rheumatoid arthritis; UA, undifferentiated arthritis; ReA, Reactive

arthritis; PsA, psoriatic arthritis; SpA, spondyloarthritis.

Conclusions: Sick leave in IA is common, even six months after diagnosis. Predictors for sick leave after six months were associated with lifestyle and level of education rather than factors commonly considered to be predictive for unfavourable arthritis outcomes. In early IA care, health care providers should focus not only on disease activity, but also on work ability and early facilitation efforts at work.

Disclosure of Interest: E. S. Norli: None declared, G. Hetland Brinkmann: None declared, T. K. Kvien Consultant for: Tore K Kvien has received fees for speaking and/or consulting from AbbVie, Biogen, BMS, Boehringer Ingelheim, Celltrion, Eli Lilly, Epirus, Janssen, Merck-Serono, MSD, Mundipharma, Novartis, Oktal, Orion Pharma, Hospira/Pfizer, Roche, Sandoz and UCB, S. Lillegraven: None declared, O. Bjørneboe: None declared, A. Julsrud Haugen: None declared, H. Nygaard: None declared, C. Thunem: None declared, E. Lie: None declared, M. Mjaavatten: None declared

DOI: 10.1136/annrheumdis-2017-eular.1986

\section{WEDNESDAY, 14 JUNE 2017 \\ Comorbidities: having one RMD is enough - we don't need anything else}

\section{OP0072-PARE PREGNANCY AND PARENTING WITH ARTHRITIS - DEVELOPING AN EDUCATIONAL RESOURCE FOR PATIENT BY PATIENTS}

L. Proulx, N. Robertson, D.P. Richards, L. Wilhelm, J. Gunderson, C. Reece, A. Sirois, A. McKinnon. Canadian Arthritis Patient Alliance, Ottawa, Canada

Background: For any individual, the decision to start a family is an important one. For individuals with arthritis, the decision to start a family is even more difficult. Many decisions need to be taken, including the risks of taking or not taking medication while trying to conceive and during pregnancy, and the ability to carry out their role as a parent. Few resources exist to help individuals navigate these important, life-changing decisions $s^{1,2}$. It is for this reason and through our collective experience as people living with arthritis that the Canadian Arthritis Patient Alliance (CAPA) launched a project on pregnancy and parenting with arthritis. The first phase of the project involved a survey ${ }^{3}$ to identify patient information needs as it relates to pregnancy and parenting. The second phase focused on the creation of a medically-reviewed resource for people living with arthritis.

Objectives: An educational resource was developed for patients by patients living with inflammatory arthritis. The resource was medically reviewed by healthcare professionals.

Methods: Priority was placed on developing content for the topics identified as "very important" and "important" from the pregnancy and parenting survey. One Board member acted as project manager to develop the resource content and obtain input from people living with arthritis, researchers and rheumatologists. Methods to obtain input include software tools, e-mails and in person meetings. The educational resource was reviewed by medical experts to improve overall reliability and uptake.

Results: The educational resource is divided in two sections - one focused on pregnancy and the other on parenting. The pregnancy section includes information on fertility and family planning, talking to your partner about parenting, medication use during pregnancy and breastfeeding, managing arthritis during pregnancy and labour and delivery. The parenting section provides a variety of "life hacks" or tips for the physical care of children and dealing with fatigue and flares as well as impact of living with arthritis on a patient's children. Ongoing efforts will be made to promote the resource and use will be monitored through social media, website metrics and surveys.

Conclusions: CAPA developed a resource for people living with arthritis regarding pregnancy and parenting. CAPA aims to raise the profile of this issue and help people living with arthritis engage in dialogue with their healthcare providers during these critical life events. It is expected that use of the resource will enable shared decision-making, improve communication with health care professionals, and reduce overall stress for people living with arthritis and their families.

References:

[1] Ackerman IN, Ngian GS, Van Doornum S, Briggs AM (2015). A systematic review of interventions to improve knowledge and self-management skills concerning contraception, pregnancy and breastfeeding in people with rheumatoid arthritis. (Clin Rheumatol).

[2] Backman, C.L., Del Fabro Smith, L., Smith, S., Montie, P.L. \& Suto, M. (2007). Experiences of mothers living with inflammatory arthritis. Arthritis \& Rheumatism (Arthritis Care \& Research), 57, 381-388.

[3] Poster from the Canadian Rheumatology Association meeting, February 2015 - Pregnancy and Parenting with Arthritis: Bridging the Information Gap.

Disclosure of Interest: None declared

DOI: 10.1136/annrheumdis-2017-eular.2563 